Editorial

\title{
Special Issue on Wastewater Treatment and Reuse Technologies
}

\author{
Faisal I. Hai ${ }^{1, *}$, Kazuo Yamamoto ${ }^{2}$ and Jega Veeriah Jegatheesan ${ }^{3}$ \\ 1 Strategic Water Infrastructure Lab, School of Civil, Mining and Environmental Engineering, \\ University of Wollongong, Wollongong, NSW 2522, Australia \\ 2 Department of Urban Engineering, University of Tokyo, Tokyo 113-0033, Japan; \\ yamamoto@esc.u-tokyo.ac.jp \\ 3 School of Engineering, RMIT University, Melbourne, VIC 3000, Australia; jega.jegatheesan@rmit.edu.au \\ * Correspondence: faisal@uow.edu.au; Tel.: +61-2-4221-3054
}

Received: 25 April 2018; Accepted: 28 April 2018; Published: 1 May 2018

\section{Introduction}

Wastewater treatment allows for the safe disposal of municipal and industrial wastewater to protect public health and the ecosystem. Reclaimed or recycled water and adequately treated wastewater is reused for a variety of applications, including landscaping, irrigation, and recharging groundwater aquifers. In many parts of the world, the problem of water scarcity is being exacerbated by urban growth and increasingly erratic rainfall patterns due to climate change. This crisis has generated an ever-increasing drive for the use of alternative water sources, especially wastewater reclamation. However, water reuse practices raise concern due to the potential adverse health effects associated with wastewater-derived resistant pollutants. Conventional sewage treatment plants can effectively remove total levels of organic carbon and nitrogen, as well as achieve some degree of disinfection. However, these plants have not been specifically designed to remove priority pollutants. Thus, the development of advanced wastewater treatment processes is necessary.

This special issue on Wastewater Treatment and Reuse Technologies includes 12 publications from esteemed research groups around the globe. The articles belong to the following broad categories: biological treatment process parameters, sludge management and disinfection, removal of trace organic contaminants, removal of heavy metals, and synthesis and fouling control of membranes for wastewater treatment.

\section{Biological Treatment Process Parameters}

The concentration of dissolved oxygen (DO) in the aeration tank(s) of an activated sludge system is one of the most important process control parameters. Rapid and precise control of DO is important for improving the efficiency of wastewater treatment and reducing the aeration energy cost, which is one of the major wastewater treatment plant operating costs [1]. In contrast to the traditional Proportional-Integral-Derivative (PID) controller, a Radial Basis Function (RBF) neural network (NN)-based adaptive PID (RBFNNPID) algorithm was proposed and simulated by Du et al. [2] in their paper on "Dissolved Oxygen Control in Activated Sludge Process Using a Neural Network-Based Adaptive PID Algorithm". Simulation results showed the developed control algorithm had better tracking, anti-disturbance and robustness performance. The practicability of this model developed by Du et al. [2] is evidenced by the fact that it has shown promising results in ongoing field testing at the Pingliang Wastewater Treatment Plant in Gansu province, China.

A range of centralised and decentralised systems are available for wastewater treatment and disposal. Selecting the right system requires a comprehensive and unbiased assessment of the alternatives. Decentralised treatment plants may be more suitable for small communities, considering 
their economic and management capacities [3]. Simultaneous energy recovery and wastewater treatment make the application of anaerobic biotechnology interesting [4]. In this context, Li and Lu [5], through their study on the "Effect of Seasonal Temperature on the Performance and on the Microbial Community of a Novel AWFR for Decentralized Domestic Wastewater Pretreatment", propose that compared to high-rate anaerobic reactors, anaerobic filters may be more suitable as a decentralised wastewater treatment system due to their simpler design, smaller footprint and ease of maintenance. The system showed significant chemical oxygen demand reduction capacity from wastewater, but performance was susceptible to seasonal temperature variations: a longer hydraulic retention time was required in winter. Applying a high-throughput sequencing technique, $\mathrm{Li}$ and $\mathrm{Lu}$ [5] provided insight into treatment performance compared to the microbial community composition of the bioreactor.

\section{Sludge Management and Disinfection}

Conventional water and wastewater treatment processes rely on extensive chemical disinfection to comply with stringent microbiological safety standards for drinking water production and wastewater reuse, respectively [6]. The traditional disposal methods of sludge generated from wastewater treatment plants on one hand constitute a major cost and on the other hand pose potential environmental risks that could result from various pollutants, such as pathogenic microorganisms, organic pollutants, and heavy metals [7]. Recently, hydrothermal carbonization has been suggested as a cost-effective and eco-friendly solution for this sewage sludge management challenge. In their article, "Removal of Escherichia coli by Intermittent Operation of Saturated Sand Columns Supplemented with Hydrochar Derived from Sewage Sludge", Chung et al. [8] evaluated hydrochar derived from sewage sludge as an additive adsorbent in sand filtration setups for Escherichia coli removal during water treatment. Supplementation of activated hydrochar in a sand filtration unit significantly improved E. coli removal efficiency. Given that pathogen removal based on the use of hydrochar is a new concept, Chung et al. [8] recommended follow up investigations on the optimization of the process parameters and the durability of the filtration unit for practical implementation in developing countries.

\section{Removal of Trace Organic Contaminants}

In recent years, the occurrence of trace organic contaminants (TrOCs) such as pharmaceuticals, personal care products, pesticides, industrial chemicals and steroid hormones in raw and inadequately treated wastewater have raised significant concern $[9,10]$. These TrOCs can adversely affect aquatic ecosystems and human health [11-13]. Conventional wastewater treatment plants cannot effectively remove TrOCs. In an article entitled "Degradation of Trace Organic Contaminants by a Membrane Distillation-Enzymatic Bioreactor", Asif et al. [14] developed an enzymatic membrane bioreactor for effective degradation of TrOCs. This study reported, for the first time, the additional benefits of coupling a 'high-retention' membrane compared to the micro and ultrafiltration membranes usually integrated with bioreactors. High retention membranes are expected to retain TrOCs effectively and thus remove them from the aqueous phase. However, Asif et al. [14], demonstrated that coupling a high retention membrane (e.g., membrane distillation) also helps boost biodegradation of TrOCs, perhaps by ensuring close and prolonged contact between the enzyme and the TrOCs.

Through their contribution, "Formulation of Laccase Nanobiocatalysts Based on Ionic and Covalent Interactions for the Enhanced Oxidation of Phenolic Compounds", Moreira et al. [15] demonstrated approaches to stabilize the xenobiotics removal performance of oxidative enzymes such as laccase. They compared several techniques of laccase immobilization on different superparamagnetic and non-magnetic nanoparticles based on ionic exchange and covalent bonding. A major advantage was that the immobilized laccase was magnetically recoverable from solution and, thus, could be reused in repeated cycles of phenol removal from wastewater. A particularly original aspect of the study was the assessment of the environmental impacts associated with the production of silica-coated magnetic nanoparticles. It was revealed that the use of energy and chemicals for the synthesis of 
laccase preparations were the major contributors of the environmental burden associated with the use of this technology.

Reverse osmosis (RO) concentrate from wastewater reuse facilities contains concentrated emerging pollutants, such as pharmaceuticals [16]. In an article entitled "Removal of Crotamiton from Reverse Osmosis Concentrate by a $\mathrm{TiO}_{2}$ /Zeolite Composite Sheet", Xiang et al. [17] assessed the removal of the antipruritic agent crotamiton from $\mathrm{RO}$ concentrate using a $\mathrm{TiO}_{2} /$ zeolite composite sheet. The $\mathrm{TiO}_{2} /$ zeolite composite sheet showed excellent performance for crotamiton adsorption without obvious inhibition by other components in the $\mathrm{RO}$ concentrate. With ultraviolet irradiation, crotamiton was simultaneously removed through adsorption and photocatalysis. The major degradation intermediates were also adsorbed by the composite sheet, i.e., the risk of secondary pollution caused by any harmful intermediates produced during advanced oxidation processes was mitigated.

Constructed wetlands are a cost-effective wastewater treatment alternative due to their low operational cost, reduced energy consumption, and low sludge production [18]. Toro-Vélez et al. [19], in their study "Longitudinal Removal of Bisphenol-A and Nonylphenols from Pretreated Domestic Wastewater by Tropical Horizontal Sub-Surface Constructed Wetlands", assessed the removal of two endocrine disrupting TrOCs, namely, Bisphenol A and nonylphenols, by an alternative wastewater treatment option: a constructed wetland. Toro-Vélez et al. [19] confirmed the significant removal of the target pollutants from wastewater by this process. Through a pilot study, they demonstrated that a native plant from the tropics could contribute to the enhanced removal of TrOCs by constructed wetlands.

\section{Removal of Heavy Metals}

Acid mine drainage generated by industrial mines is characterized by its highly acidic nature and toxic heavy metal content [20]. With their high solubility as well as non-biodegradable and bio-accumulative properties, heavy metals are a serious threat to human health and the environment. Ciosek et al. [21] demonstrated the performance of natural zeolite (clinoptilolite) to remove multiple heavy metallic ions commonly found in acid mine drainage in their article "An Innovative Dual-Column System for Heavy Metallic Ion Sorption by Natural Zeolite". A novel dual-column sorption system was designed to overcome some of the shortcomings of existing column experimental designs. In contrast to most previous single-component sorption set-ups, this study evaluated the simultaneous sorption process by natural zeolite of the five most commonly occurring heavy metallic ions found in acid mine drainage, namely, $\mathrm{Pb}^{2+}, \mathrm{Cu}^{2+}, \mathrm{Fe}^{3+}, \mathrm{Ni}^{2+}$ and $\mathrm{Zn}^{2+}$. This paper demonstrated the effectiveness and removal efficiency of the proposed system and provided insights into heavy metal ion selectivity and treatment system breakthroughs.

Included in this special issue is another article on heavy metal remediation from industrial wastewater by Elyahyaoui et al. [22]. Phosphate materials, particularly calcium phosphate, have been studied as effective adsorbents for heavy metals from wastewaters and polluted soils. However, there is a lack of understanding of the mechanisms of heavy metal immobilization that involves protonation/deprotonation of surface hydroxyl groups and their interaction with the metal oxyanion. Therefore the article entitled "Adsorption of Chromium (VI) on Calcium Phosphate: Mechanisms and Stability Constants of Surface Complexes" [22] investigated the mechanisms of complexation of hexavalent chromium with low-crystallized octacalcium phosphate. The obtained results suggested that $\mathrm{Cr}$ (VI) adsorption on octacalcium phosphate was of an electrostatic nature in acidic solutions, and of a chemical nature in lower acidic to alkaline solutions.

\section{Synthesis and Fouling Control of Membranes for Wastewater Treatment}

Seawater desalination by reverse osmosis (RO) membrane has been widely utilized to tackle the shortage of fresh water in different regions of the world. However, a large amount of brine wastewater is produced as a by-product of desalination [23]. The treatment efficiency of thermally driven processes such as membrane distillation (MD) is less dependent on feed solution concentration, and can be regarded as a promising candidate in brine wastewater treatment [24]. However, the available 
MD membranes suffer from fouling/scaling and pore wetting. Pervaporation is also a thermally driven process, but the available membranes have been developed for organic solvent dehydration (containing low water content) and, thus, are not suitable for desalination where water is the major component in-feed. The article "Suppressing Salt Transport through Composite Pervaporation Membranes for Brine Desalination" by Li et al. [25], explored a series of composite polyvinyl alcohol (PVA)/Polyvinylidene fluoride (PVDF) membranes to suppress salt transport through the membrane during brine treatment. By incorporating a small amount of graphene oxide into the PVA matrix, the authors further improved salt rejection during extended desalination operation. The pervaporation membranes fabricated in this study could potentially be used for brine treatment.

As noted above, one of the concerns with respect to the full scale commercialization of the membrane distillation technique for wastewater treatment is the lack of membranes ensuring long term stable operation. To this end, Eykens et al. [26], in their paper, "Functionalization of a Hydrophilic Commercial Membrane Using Inorganic-Organic Polymers Coatings for Membrane Distillation", carried out surface modification of a commercially available hydrophilic polyethersulfone membrane. Through hydrophobic coating using a commercially available technique, the surface contact angle of the membrane could be increased from $27^{\circ}$ up to $110^{\circ}$. The stability of the coating was confirmed in a $100 \mathrm{~h}$ trial as a preliminary assessment.

Low-pressure submerged microfiltration and ultrafiltration applications have become a mainstream technology for surface-water treatment, pretreatment prior to reverse osmosis (RO), and membrane bioreactors (MBRs) for wastewater treatment. Membrane fouling is the Achilles heel of submerged membrane technologies [27,28]. The article "The Performance and Fouling Control of Submerged Hollow Fiber (HF) Systems: A Review" by Akhondi et al. [29] provides a comprehensive landscape of current state-of-the-art of submerged hollow fiber membrane systems. This review serves as a guide for further improvements in submerged membranes and their applications.

Acknowledgments: This work was partially funded by seed grants from GeoQuEST research Centre and the Faculty of Engineering and Information Sciences of the University of Wollongong, Australia. Sincere thanks are due to all the authors and peer reviewers for their valuable contributions to this special issue. Finally, we place on record our gratitude to the editorial team of Applied Sciences.

Conflicts of Interest: The authors declare no conflict of interest.

\section{References}

1. Jegatheesan, V.; Visvanathan, C. Process fundamentals: From conventional biological wastewater treatment to MBR. In Membrane Biological Reactors: Theory, Modeling, Design, Management and Applications to Wastewater Reuse; Hai, F.I., Yamamoto, K., Lee, C., Eds.; IWA Publishing: London, UK, 2014; pp. 29-53, ISBN 9781780400655.

2. Du, X.; Wang, J.; Jegatheesan, V.; Shi, G. Dissolved oxygen control in activated sludge process using a neural network-based adaptive PID algorithm. Appl. Sci. 2018, 8, 261. [CrossRef]

3. Orth, H. Centralised versus decentralised wastewater systems? Water Sci. Technol. 2007, 56, $259-266$. [CrossRef] [PubMed]

4. Gao, W.; Liao, B.; Hai, F.I. Anaerobic mbrs. In Membrane Biological Reactors: Theory, Modeling, Design, Management and Applications to Wastewater Reuse; Hai, F.I., Yamamoto, K., Lee, C., Eds.; IWA Publishing: London, UK, 2014; pp. 335-377, ISBN 9781780400655.

5. $\mathrm{Li}, \mathrm{J} . ; \mathrm{Lu}, \mathrm{X}$. Effect of seasonal temperature on the performance and on the microbial community of a novel AWFR for decentralized domestic wastewater pretreatment. Appl. Sci. 2017, 7, 605.

6. Hai, F.; Riley, T.; Shawkat, S.; Magram, S.; Yamamoto, K. Removal of pathogens by membrane bioreactors: A review of the mechanisms, influencing factors and reduction in chemical disinfectant dosing. Water 2014, 6, 3603-3630. [CrossRef]

7. Semblante, G.U.; Hai, F.I.; Huang, X.; Ball, A.S.; Price, W.E.; Nghiem, L.D. Trace organic contaminants in biosolids: Impact of conventional wastewater and sludge processing technologies and emerging alternatives. J. Hazard. Mater. 2015, 300, 1-17. [CrossRef] [PubMed] 
8. Chung, J.; Edewi, O.; Foppen, J.; Gerner, G.; Krebs, R.; Lens, P. Removal of Escherichia coli by intermittent operation of saturated sand columns supplemented with hydrochar derived from sewage sludge. Appl. Sci. 2017, 7, 839. [CrossRef]

9. Asif, M.B.; Hai, F.I.; Singh, L.; Price, W.E.; Nghiem, L.D. Degradation of pharmaceuticals and personal care products by white-rot fungi-A critical review. Curr. Pollut. Rep. 2017, 3, 88-103. [CrossRef]

10. Asif, M.B.; Hai, F.I.; Hou, J.; Price, W.E.; Nghiem, L.D. Impact of wastewater derived dissolved interfering compounds on growth, enzymatic activity and trace organic contaminant removal of white rot fungiA critical review. J. Environ. Manag. 2017, 201, 89-109. [CrossRef] [PubMed]

11. Luo, Y.; Guo, W.; Ngo, H.H.; Nghiem, L.D.; Hai, F.I.; Zhang, J.; Liang, S.; Wang, X.C. A review on the occurrence of micropollutants in the aquatic environment and their fate and removal during wastewater treatment. Sci. Total Environ. 2014, 473, 619-641. [CrossRef] [PubMed]

12. Alexander, J.T.; Hai, F.I.; Al-aboud, T.M. Chemical coagulation-based processes for trace organic contaminant removal: Current state and future potential. J. Environ. Manag. 2012, 111, 195-207. [CrossRef] [PubMed]

13. Pal, A.; Gin, K.Y.-H.; Lin, A.Y.-C.; Reinhard, M. Impacts of emerging organic contaminants on freshwater resources: Review of recent occurrences, sources, fate and effects. Sci. Total Environ. 2010, 408, 6062-6069. [CrossRef] [PubMed]

14. Asif, M.; Hai, F.; Kang, J.; van de Merwe, J.; Leusch, F.; Yamamoto, K.; Price, W.; Nghiem, L. Degradation of trace organic contaminants by a membrane distillation-Enzymatic bioreactor. Appl. Sci. 2017, 7, 879. [CrossRef]

15. Moreira, M.; Moldes-Diz, Y.; Feijoo, S.; Eibes, G.; Lema, J.; Feijoo, G. Formulation of laccase nanobiocatalysts based on ionic and covalent interactions for the enhanced oxidation of phenolic compounds. Appl. Sci. 2017, 7, 851. [CrossRef]

16. Hai, F.I.; Nghiem, L.D.; Khan, S.J.; Price, W.E.; Yamamoto, K. Wastewater reuse: Removal of emerging trace organic contaminants. In Membrane Biological Reactors: Theory, Modeling, Design, Management and Applications to Wastewater Reuse; Hai, F.I., Yamamoto, K., Lee, C., Eds.; IWA Publishing: London, UK, 2014; pp. 165-205, ISBN 9781780400655.

17. Xiang, Q.; Fukahori, S.; Yamashita, N.; Tanaka, H.; Fujiwara, T. Removal of crotamiton from reverse osmosis concentrate by a $\mathrm{TiO}_{2}$ /zeolite composite sheet. Appl. Sci. 2017, 7, 778. [CrossRef]

18. Saeed, T.; Sun, G. A review on nitrogen and organics removal mechanisms in subsurface flow constructed wetlands: Dependency on environmental parameters, operating conditions and supporting media. J. Environ. Manag. 2012, 112, 429-448. [CrossRef] [PubMed]

19. Toro-Vélez, A.; Madera-Parra, C.; Peña-Varón, M.; García-Hernández, H.; Lee, W.; Walker, S.; Lens, P. Longitudinal removal of bisphenol-a and nonylphenols from pretreated domestic wastewater by tropical horizontal sub-surfaceconstructed wetlands. Appl. Sci. 2017, 7, 834. [CrossRef]

20. Johnson, D.B.; Hallberg, K.B. Acid mine drainage remediation options: A review. Sci. Total Environ. 2005, 338, 3-14. [CrossRef] [PubMed]

21. Ciosek, A.; Luk, G. An innovative dual-column system for heavy metallic ion sorption by natural zeolite. Appl. Sci. 2017, 7, 795. [CrossRef]

22. Elyahyaoui, A.; Ellouzi, K.; Al Zabadi, H.; Razzouki, B.; Bouhlassa, S.; Azzaoui, K.; Mejdoubi, E.; Hamed, O.; Jodeh, S.; Lamhamdi, A. Adsorption of chromium (vi) on calcium phosphate: Mechanisms and stability constants of surface complexes. Appl. Sci. 2017, 7, 222. [CrossRef]

23. Lattemann, S.; Höpner, T. Environmental impact and impact assessment of seawater desalination. Desalination 2008, 220,1-15. [CrossRef]

24. Duong, H.C.; Hai, F.I.; Al-Jubainawi, A.; Ma, Z.; He, T.; Nghiem, L.D. Liquid desiccant lithium chloride regeneration by membrane distillation for air conditioning. Sep. Purif. Technol. 2017, 177, 121-128. [CrossRef]

25. Li, L.; Hou, J.; Ye, Y.; Mansouri, J.; Zhang, Y.; Chen, V. Suppressing salt transport through composite pervaporation membranes for brine desalination. Appl. Sci. 2017, 7, 856. [CrossRef]

26. Eykens, L.; Rose, K.; Dubreuil, M.; De Sitter, K.; Dotremont, C.; Pinoy, L.; Van der Bruggen, B. Functionalization of a hydrophilic commercial membrane using inorganic-organic polymers coatings for membrane distillation. Appl. Sci. 2017, 7, 637. [CrossRef]

27. Hai, F.I.; Yamamoto, K.; Fukushi, K.; Nakajima, F. Fouling resistant compact hollow-fiber module with spacer for submerged membrane bioreactor treating high strength industrial wastewater. J. Membr. Sci. 2008, 317, 34-42. [CrossRef] 
28. Kimura, K.; Meng, F.; Chang, I.-S.; Lee, C.-H. Monitoring, characterization and control of membrane biofouling in mbr. In Membrane Biological Reactors: Theory, Modeling, Design, Management and Applications to Wastewater Reuse; Hai, F.I., Yamamoto, K., Lee, C., Eds.; IWA Publishing: London, UK, 2014; pp. 97-136, ISBN 9781780400655.

29. Akhondi, E.; Zamani, F.; Tng, K.; Leslie, G.; Krantz, W.; Fane, A.; Chew, J. The performance and fouling control of submerged hollow fiber (hf) systems: A review. Appl. Sci. 2017, 7, 765. [CrossRef] 